\title{
AN EPIDERMAL FACTOR WHICH STIMULATES THE SYNTHESIS OF COLLAGENASE IN FIBROBLASTS IN A RECONSTITUTED DERMAL MODEL
}

\author{
Keiko Shimizu-Nishikawa ${ }^{1}$ and Katsutoshi Yoshizato ${ }^{2}$ \\ Developmental Biology Laboratory, Department of Biology, Faculty of Science, Tokyo Metropolitan \\ University, Fukazawa, Setagayaku, Tokyo 158, Japan
}

\begin{abstract}
A dermal model was prepared by embedding rat dermal fibroblasts in three-dimensional lattices of hydrated collagen fibrils. A factor (or factors) which stimulates collagenolysis of the dermal model was found in the epidermal-cell-conditioned medium (ECCM). The factor was secreted from epidermal cells into culture media at a time point between 6 and 7 days of culture. The gel filtration chromatography indicates that the molecular weight of the factor is around $48 \mathrm{~K}$. Collagenolysis was not stimulated when collagen gels were incubated in a mixture of conditioned media from cultures of epidermal cells and of fibroblasts in the dermal model, indicating that the factor is not a latent collagenase and is not an acitivator of the latent enzyme. That the factor is a stimulator of collagenase synthesis in fibroblasts was shown in experiments with cycloheximide and cortisol, where these chemicals completely abolished the stimulator activity in ECCM. Unlike fibroblasts in collagen gels, monolayered fibroblasts on plastic dishes were not sensitive to the factor, suggesting that the cell shape is essential for fibroblasts to respond to the factor. Several lines of evidence indicate that the epidermal factor is a unique stimulator of collagenase biosynthesis in fibroblasts which has not been reported hitherto.
\end{abstract}

Collagenase is one of the principal enzymes in the metabolism of connective tissues in both physiological and pathological processes. Many regulators of activity and production of collagenase have been reported (28): specific inhibitors such as tissue inhibitor of metallo-

\footnotetext{
${ }^{1}$ Present address: Department of Biological Sciences, University of Illinois at Chicago, Chicago, Illinois 60680 , U.S.A.

${ }^{2}$ All correspondence should be addressed to $\mathrm{K}$. Yoshizato whose present address is: Developmental Cell Biology Laboratory, Zoological Institute, Faculty of Science, Hiroshima University, Higashisendamachi, Nakaku, Hiroshima 730, Japan
}

proteinase (TIMP) $(38,55)$, steroid hormones as the suppressor $(3,11)$ and several stimulators such as prostaglandins (15), cytokines (27, $30)$ and lymphokines $(13,16,37,54)$. These regulators of collagenase have been usually found in tissues or cells cultured on plastic which is a completely artificial substrate.

Elsdale and Bard (17) tried to elaborate a method where dermal fibroblasts can be cultured in an environment similar to the in vivo condition. Thus, these authors developed a dermal model where fibroblasts are populated in three-dimensional lattices of hydrated collagen fibrils. The dermal model has been well characterized morphologically and biochemi- 
cally $(20-22,24,35,47,48,58-60)$. This model was further progressed in a skin equivalent by Bell and his associate (4), where the dermal model is overlaid with epidermal cells. In this skin model, epidermal cells adhere to the dermal model, form a multilayered epidermal sheet, and differentiate (5).

When the skin model was prepared with rat cells, we noticed an unexpectedly high level of collagenolytic activity, which led to a complete dissolution of the model (58). This activity was due to collagenase and was successfully suppressed by adding cortisol to the culture medium. In the present study, regulation of the collagenase activity in the skin model is further investigated. A new and unique stimulator of collagenase synthesis in fibroblasts was found in the culture media of epidermal cells. Some of its biological and biochemical characteristics are described in this report.

\section{MATERIALS AND METHODS}

\section{Chemicals, Reagents and Culture Materials}

Trypsin (EC 3.4.21.4) was obtained from Difco (Detroit); dispase (EC 3.4.24.4) from Godo Shusei (Tokyo); cortisol and molecular weight markers (bovine serum albumin, chymotrypsinogen A, myoglobin, ribonuclease $\mathrm{A}$ and cyanocobalamin) from Sigma Chemical (St. Louis, MO); Percoll and resins of Sephadex G-100 from Pharmacia Fine Chemicals (Uppsala); fetal calf serum (FCS) from Nippon Biotest (Tokyo); Dulbecco's modified Eagle's medium (DMEM) from GIBCO (Grand Island, NY); Hepes ( $\mathrm{N}$-2hydroxyethyl piperazine- $N^{\prime}$-2-ethanesulfonic acid) from Dojin Chemical Institute (Kumamoto); antibiotics (penicillin and streptomycin) from Meiji Seika Kaisha (Tokyo); a specific inhibitor of collagenase from the bovine dental pulp (33), a gift from Dr T. Hayakawa; Cellgen $(0.5 \%$ type I collagen solution) from Koken (Tokyo); Coster 12-well tissue culture clusters from Data Packing (Cambridge, MA); 24-well multiplates from Terumo (Tokyo); ultrafiltration membranes and Centriprep-10 from Grace Company (Lexington); and all other chemicals were of reagent grade, purchased from Wako Pure Chemical Industries (Tokyo) or Nacalai Tesque (Kyoto).

\section{Animals}

Newborn Fisher rats (F344, specific pathogenfree, 2-3 days after birth) were purchased from Nippon Biosup Center (Tokyo).

\section{Cell Culture}

Newborn rat skin was separated into epidermis and dermis with forceps after dispase digestion according to Kitano and Okada (34). Epidermal cells were isolated from epidermis with trypsin digestion (50), and were further purified by Percoll density gradient centrifugation (39). No fibroblasts were noticed at least up to 10 days when the preparation of epidermal cells thus obtained was cultured. Fibroblasts were collected as cells migrating from dermal explants and were subcultured (57). Both cells were stored in liquid nitrogen until use. Cells were cultured at $37^{\circ} \mathrm{C}$ in a humidified atmosphere of $5 \% \quad \mathrm{CO}_{2} / 95 \%$ air. DMEM containing $100 \mathrm{U} / \mathrm{ml}$ penicillin, 100 $\mu \mathrm{g} / \mathrm{ml}$ streptomycin, $10 \mathrm{mM} \mathrm{NaHCO}, 20$ $\mathrm{mM}$ Hepes and $10 \%$ FCS was used as culture medium for epidermal cells and fibroblasts.

\section{Preparation of ECCM (Epidermal-Cell-con- ditioned Medium)}

Epidermal cells were plated at $1.5 \times 10^{6} \mathrm{per}$ well (diameter $22 \mathrm{~mm}$ ) with $2 \mathrm{ml}$ of medium and were allowed to attach for $24 \mathrm{~h}$. Then the culture medium was replaced by fresh medium $(2 \mathrm{ml})$ and the cells were further cultured for the days indicated in each experiment. Culture media were collected and centrifuged at $1,500 \mathrm{~g}$ for $15 \mathrm{~min}$. The supernatant was stored at $-20^{\circ} \mathrm{C}$ and was used as ECCM.

\section{Preparation of Dermal Models}

Dermal models were prepared as described previously $(21,58)$. Fibroblasts were suspended at $2.5 \times 10^{5}$ cells $/ \mathrm{ml}$ in the culture medium containing $0.2 \%$ collagen. A solution of $500 \mu 1$ of the cell suspension was poured into wells (diameter $15 \mathrm{~mm}$ ) and was allowed to form collagen fibrils at $37^{\circ} \mathrm{C}$. After $24 \mathrm{~h}$, the models were overlaid with $0.5 \mathrm{ml}$ of fresh culture medium or ECCM and incubated for the indi- 
cated period. Dermal-model-conditioned-medium (DMCM) was prepared by incubating the dermal models for 4 days at $37^{\circ} \mathrm{C}$. Media were obtained by centrifuging models at $17,000 \mathrm{~g}$ for $10 \mathrm{~min}$ and used as DMCM in the experiment shown in Fig. 3.

\section{Gel Filtration of ECCM}

All manipulations were carried out at $4^{\circ} \mathrm{C}$. ECCM was concentrated about 25 -fold by an Amicon ultrafiltration cell with a YM-10 Diaflo membrane. Four milliliters of concentrated ECCM was applied onto a $1.6 \times 90 \mathrm{~cm}$ Sephadex G-100 column equilibrated with an elution buffer containing $0.15 \mathrm{M} \mathrm{NaCl}$ and $10 \mathrm{mM}$ Tris-HCl, pH 7.4. The column had been calibrated with molecular weight markers: bovine serum albumin $(67 \mathrm{~K})$, chymotrypsinogen $\mathrm{A}(25 \mathrm{~K})$, myoglobin $(17 \mathrm{~K})$, ribonuclease $\mathrm{A}(13.7 \mathrm{~K})$, and cyanocobalamin $(1.3 \mathrm{~K})$. For the assay of collagenase-stimulating activity, each fraction was concentrated and was exchanged with DMEM by using a Centriprep-10.

\section{Assay for Collagenolytic Activity of Dermal Models}

Dermal models were centrifuged at $17,000 \mathrm{~g}$ for $10 \mathrm{~min}$. The supernatants were hydrolyzed in $6 \mathrm{~N} \mathrm{HCl}$ at $110^{\circ} \mathrm{C}$ for $24 \mathrm{~h}$. Concentrations of hydroxyproline in the hydrolysate were determined by the method of Bergman and Loxley (6). The collagenolytic activity of dermal models was quantitated by the amount of hydroxyproline in the supernatants. This represents the collagenase activity, because no hydroxyproline was detected when the dermal model was incubated in the presence of a specific collagenase inhibitor purified from the bovine dental pulp. ECCM itself showed collagenolytic activity, which was less than $7 \%$ of that of the dermal model in most cases. The collagenase activity of the dermal model was obtained by subtracting the activity of ECCM when the model was incubated with ECCM.

\section{RESULTS}

Effect of ECCM on Collagenase Activity of Dermal Models

The skin model showed a high activity of col- lagenolysis. This collagenolysis resulted from degradation of collagen fibrils by collagenase produced by fibroblasts and/or by epidermal cells, because the presence of a collagenasespecific inhibitor ( 1 unit $/ \mathrm{ml}$ ) or cycloheximide $(100 \mathrm{ng} / \mathrm{ml})$ completely inhibited the collagenolysis. Previous study has also shown that the skin model expresses collagenase activity which is higher than that obtained by arithmetical summation of activities of the epidermal cells and dermal model (58). This synergetic activity of collagenase in the skin model suggests the presence of epidermis-dermis interactions for the expression of collagenase of each of both epidermal cells and fibroblasts. To biochemically clarify an aspect of this interaction, ECCM was prepared and was placed onto the dermal model. ECCM was obtained by culturing epidermal cells for 6 days in the presence or absence of FCS. ECCM markedly stimulated the collagenase activity of dermal models: about 6-fold stimulation as compared to unconditioned fresh medium was observed (Fig. 1). The presence of FCS during the culture of epidermal cells did not affect the extent of stimulation.

Fig. 2 dipicts a time course of response by fibroblasts in dermal models to ECCM. Fibroblasts started to respond to ECCM at day 3 of culture and were activated enough at day 4. In experiments described below, the collagenase activity of fibroblasts was measured at day 4 of culture with ECCM.

\section{The Presence of A Stimulator in ECCM for Collagenase Production by Fibroblasts}

The results shown in Fig. 1 and Fig. 2 suggest four possibilities as to the activation of collagenase in the dermal model. First, the latent collagenase (procollagenase) produced by fibroblasts is activated by some protease in ECCM. Second, procollagenase in ECCM is activated by proteolytic enzymes from fibroblasts. Third, the first and second possibilities occur simultaneously. Fourth, ECCM contains a stimulator which activates the synthesis of collagenase in fibroblasts in the dermal model.

To see which of the four possibilities is likely, DMCM was prepared and mixed with ECCM. The mixture was assayed for the collagenolytic activity (Fig. 3). ECCM alone 


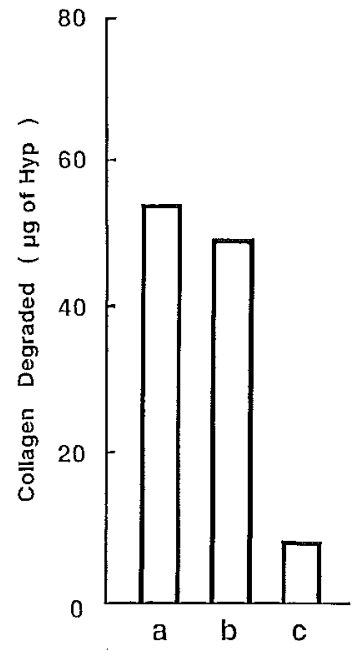

Fig. 1 Activation of dermal collagenase by epidermal-cell-conditioned medium (ECCM), ECCM was prepared in the presence $(10 \%)$ or absence of fetal calf serum (FCS) and was overlaid onto the dermal model. ECCM which had been prepared in the absence of FCS was supplemented with FCS at a final concentration of $10 \%$ and was then overlaid on the dermal model. Collagenase activity was determined at day 4 of culture as detailed in the text, and expressed as $\mu \mathrm{g}$ of hydroxyproline from the dermal model in a $15-\mathrm{mm}$ well. The values are averages of three determinations. SE was within $15 \%$ of the mean. a, ECCM with FCS; b, ECCM without FCS; $c$, unconditioned fresh medium

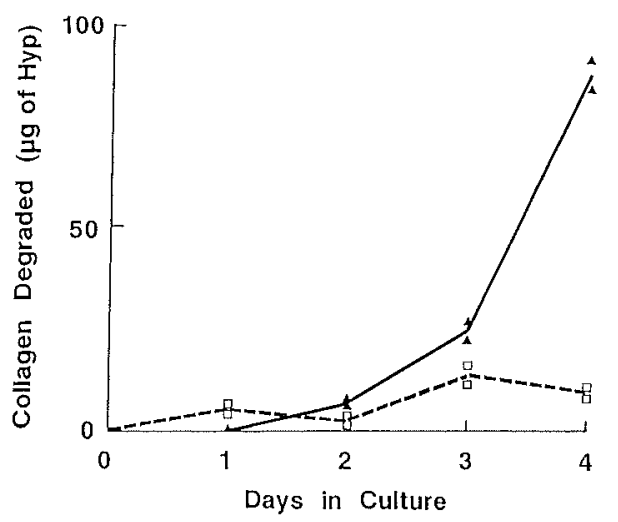

Fig. 2 Responsiveness of fibroblasts to ECCM. Dermal models were prepared and left $24 \mathrm{~h}$ before exposure to ECCM, at zero day. Each value represents a single determination. $\square-\square$, without ECCM; $\Delta$, with ECCM

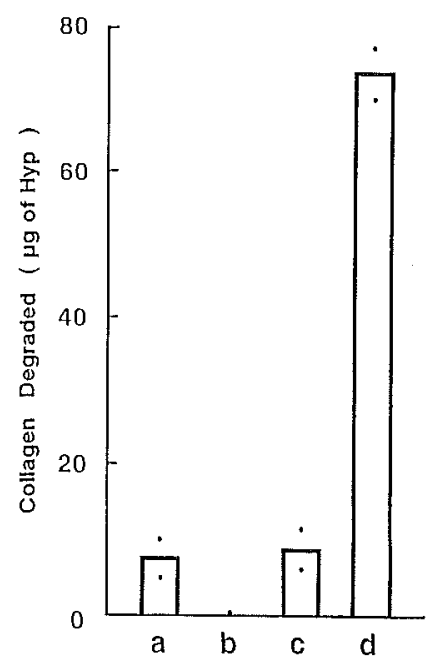

Fig. 3 Collagenase activity of ECCM and DMCM. ECCM was incubated alone, with DMCM, or with the dermal model for 4 days and the collagenase activity was then determined. Each column represents the average of two determinations shown by closed circles. a, ECCM alone; b, DMCM alone; c, ECCM with DMCM; d, ECCM with the dermal model

showed some activity, while DMCM alone had no activity. No stimulation of collagenolysis was observed in the mixture of ECCM and DMCM as compared to that of ECCM alone or that of the dermal model with ECCM where about 7.5-fold stimulation was obtained. This result supports the fourth possibility.

The presence of an epidermal stimulator for the synthesis of collagenase by the dermal model was further supported by the experiment, where dermal models were incubated with ECCM in the presence of cortisol $(200 \mathrm{ng} / \mathrm{ml})$ or cycloheximide $(3 \mu \mathrm{g} / \mathrm{ml})$. Cortisol is known to suppress the synthesis of collagenase in fibroblasts $(3,11)$. More than $95 \%$ of protein synthesis in fibroblasts was inhibited by this concentration of cycloheximide. These two chemicals almost (in case of cortisol) or completely (in case of cycloheximide) abolished the stimulator activity of ECCM (Fig. 4).

The relationship between the concentration of the stimulator in ECCM and the extent of stimulation is shown in Fig. 5. When diluted 


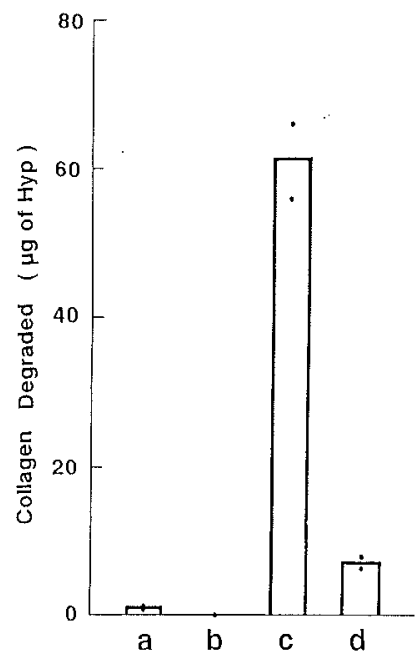

Fig. 4 Effects of cortisol or cycloheximide on the activity of ECCM. The dermal model was incubated with ECCM in the presence of cortisol (200 ng/ $\mathrm{ml})$ or cycloheximide $(3 \mu \mathrm{g} / \mathrm{ml})$ for 4 days, and was assayed for collagenase activity. Each column represents the average of two determinations shown by closed circles. a, ECCM in the presence of cortisol; b, ECCM in the presence of cycloheximide; $c$, ECCM alone; d, fresh medium

to $80 \%$ of original ECCM, ECCM showed as low as $50 \%$ stimulation of the full strength. No stimulation was observed at more than $50 \%$ dilution.

Epidermal cells were found to release this stimulator of collagenase production by fibroblasts at a time point between 5 th and 7 th day of culture but not at days earlier than this (Fig. 6). Gross appearance of epidermal cells during culture is presented in Fig. 7. Epidermal cells actively releasing the stimulation factor are larger in size and show diffused boundaries of cells in colonies.

\section{Some Characterization of the Stimulation Factor}

The factor did not lose its activity on repeated freezing-thawing (no loss up to at least 7 times operations). The factor was very heatunstable: complete inactivation occurred at $100^{\circ} \mathrm{C}$ for $10 \mathrm{~min}$.

The factor did not pass ultrafiltration membranes with a cut molecular weight of 10 $\mathrm{K}$. The molecular weight of the factor was

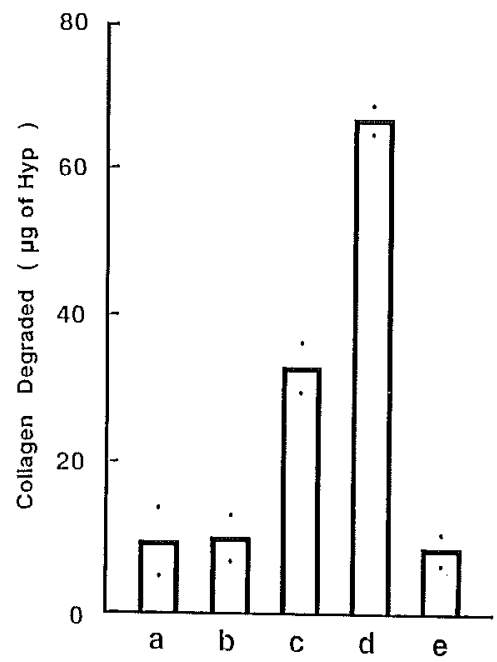

Fig. 5 Response of fibroblasts to diluted ECCM. ECCM was diluted to $80 \%$ (c), $50 \%$ (b), and $20 \%$ (a) of original strength (d) and was assayed for the collagenase stimulation activity. e, unconditioned fresh medium. Each column indicates the average of two determinations shown by closed circles.

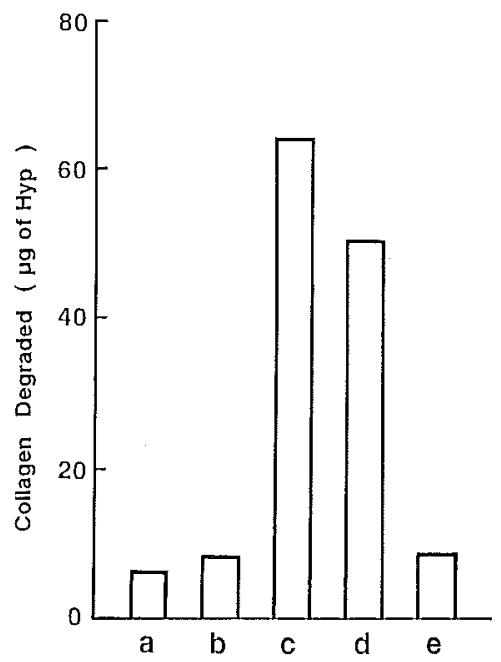

Fig. 6 Epidermal stimulator for the collagenase synthesis in fibroblasts. Epidermal cells were cultured for $24 \mathrm{~h}$ in DMEM-10\% FCS and media were replaced with fresh serum-free DMEM. The cells were cultured for days indicated below. ECCM thus obtained was assayed for the collagenase stimulating activity. The values are the averages of three determinations. SE is within $13 \%$ of the average. a, ECCM obtained by culturing epidermal cells between day 1 and day $3 ; b, E C C M$ between day 3 and day $5 ; c$, ECCM between day 5 and day $7 ; d, E C C M$ between day 1 and day 7 ; e, fresh medium 

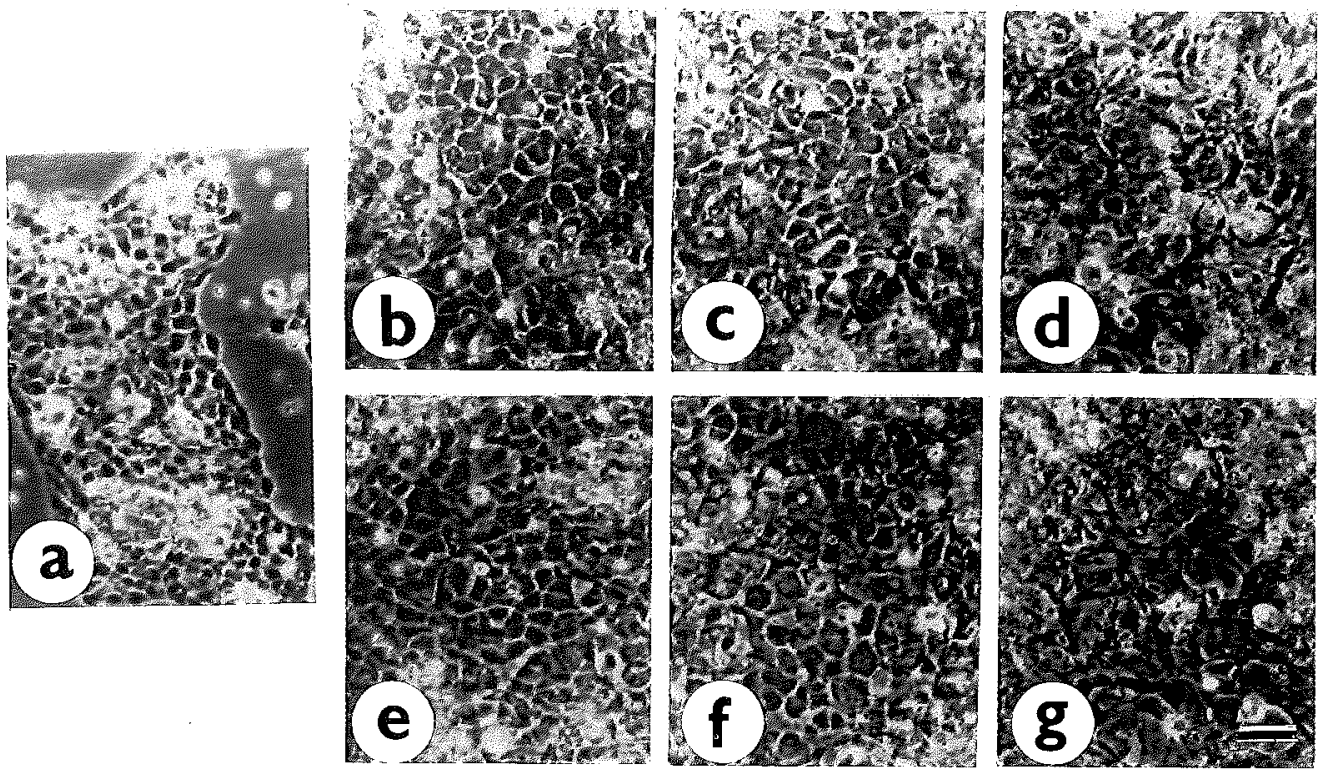

Fig. 7 Gross appearance of epidermal cells during culture. Epidermal cells were cultured in the presence or absence of FCS and were photographed at days indicated below. a through d, in the presence of FCS; e through $\mathrm{g}$, in the absence of FCS; $a$, day 1 ; b and e, day $3 ; \mathrm{c}$ and $\mathrm{f}$, day 5; d and $\mathrm{g}$, day 7 . Bar, $50 \mu \mathrm{m}$

estimated to be around $48 \mathrm{~K}$ by molecular sieve chromatography with Sephadex G-100 (Fig. 8).

Importance of Shape of Fibroblasts for Their Responsiveness to the Factor in ECCM

Fibroblasts in Fig. $9 \mathrm{~b}$ are the cells that are actively producing collagenase in response to the factor in ECCM. They are more round in shape as compared to the cells in control culture (Fig. 9a). Importance of cell shape for fibroblasts to respond to the stimulation factor is further suggested by the following experiment. Fibroblasts were cultured on plastic surface as a conventional monolayer, exposed to ECCM, and collagenolytic activity of the culture media was assayed (Fig. 10). No stimulation of collagenase production was seen at all, in contrast to fibroblasts in the dermal model which were stimulated by ECCM. The shape of fibroblasts were compared between cells on the plastic and those within collagen gels (Fig. 11). The shape was quite different: flat and with less cytoplasmic protrusions on the plastic, whereas elongated and slim and with many protrusions in the gels.

\section{DISCUSSION}

Recently, methods of culture of mammalian functional cells have been greatly improved due to discovery of several essential growth factors (23), and elucidation of the important roles of extracellular matrices (ECM) for morphology and physiology of normal mammalian cells (49). Successful attempts to reconstitute organized architectures which morphologically and biochemically mimic the corresponding organ in the living body have been reported for the liver (44), blood capillaries (18) and vascular walls (53). Bell and his associates developed a skin equivalent by seeding epidermal cells onto a dermal equivalent where dermal fibroblasts had been populated in three-dimensional lattices of hydrated collagen fibrils $(4,5)$.

During studies on a skin equivalent, we noticed unexpectedly high activity of collagenase when a skin model was reconstituted with rat cells (58). It was inferred that there was an interaction between epidermal cells and fibroblasts for the expression of collagenase in the skin model. There has been reports which describe cell-cell interactions for the 


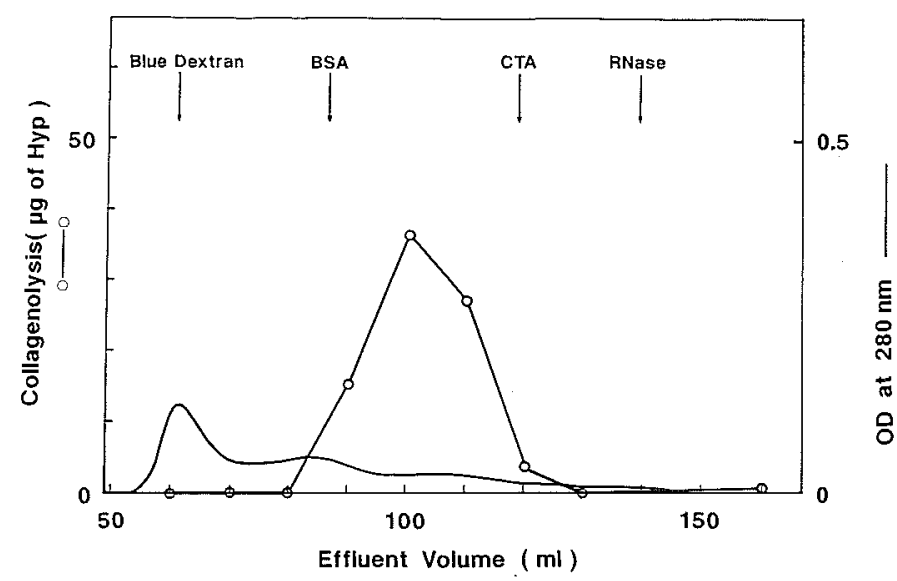

Fig. 8 Gel filtration chromatography of the stimulation factor in ECCM. ECCM was pooled and concentrated about 25 -fold, $4 \mathrm{ml}$ of which was applied to a column of Sephadex G-100 $(1.6 \times 90 \mathrm{~cm})$. Eluates were collected every $10 \mathrm{ml}$, concentrated and exchanged with DMEM by using a Centriprep-10, and assayed for the collagenase activity in fibroblasts in the dermal model. The elution positions of molecular weight markers are shown by arrows. BSA, bovine serum albumin $(67 \mathrm{~K})$; CTA, chymotrypsinogen A $(25 \mathrm{~K})$; RNase, ribonuclease $\mathrm{A}(13.7 \mathrm{~K}) .-$, absorbance at $280 \mathrm{~nm} ; \mathrm{O}_{-} \mathrm{O}$, collagenase activity in the dermal model
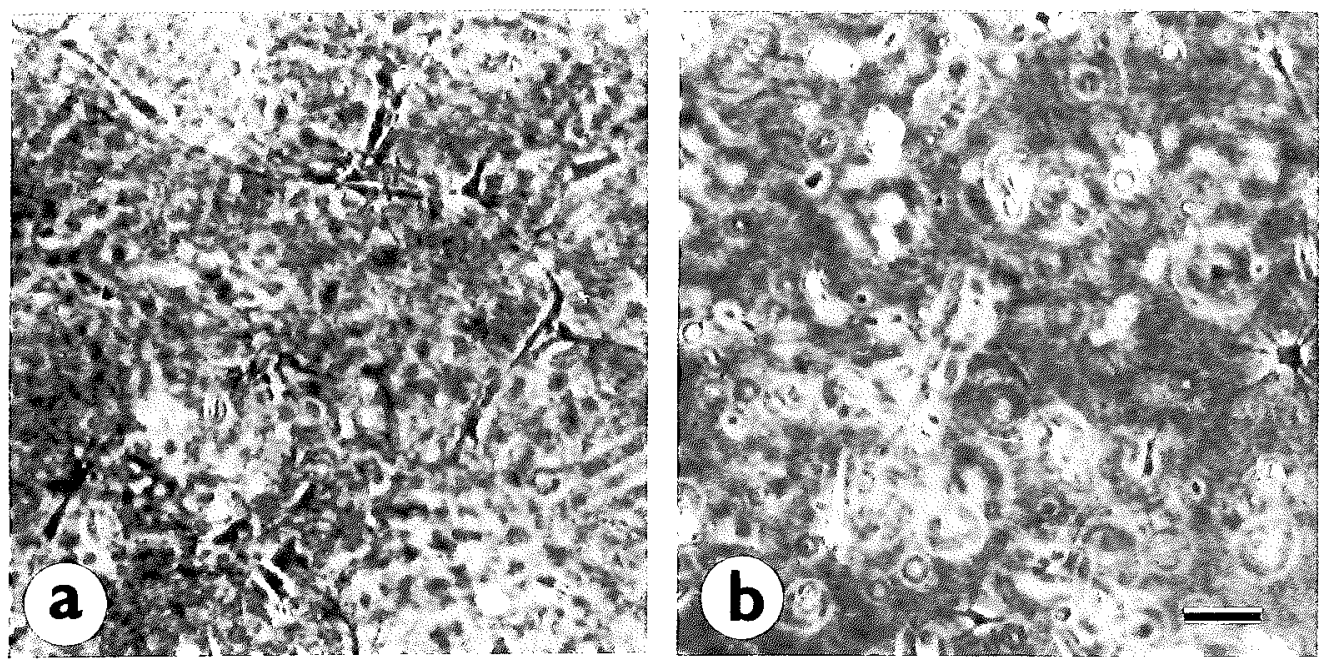

Fig. 9 Gross appearance of fibroblasts in collagen gels. Fibroblasts in the dermal model were exposed to ECCM for 4 days. The bar indicates $80 \mu \mathrm{m}$, a, with unconditioned fresh medium; b, with ECCM

collagenase production since the study by Grillo and Gross (19) where they first demonstrated that collagenase production by one cell type can be greatly modified by the presence of another cell type (56). From the viewpoint of reconstitution of the skin model, the high expression of collagenase raises a difficulty in developing structurally stable skin 


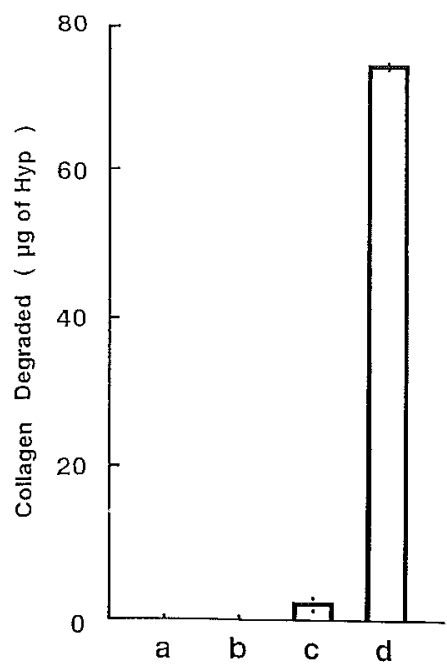

Fig. 10 Unresponsiveness of fibroblasts cultured on the plastic to the factor in ECCM. Fibroblasts $\left(9.2 \times 10^{4}\right.$ cells $)$ were cultured on the plastic (22 $\mathrm{mm}$ in diameter) or in collagen gels $(0.5 \mathrm{ml}$ in $22 \mathrm{~mm}$-dish). They were exposed to ECCM for 4 days and collagenase activity of the media was determined. Each column represents the average of two determinations shown by closed circles. a, b, fibroblasts on the plastic; $c$, d, fibroblasts in the dermal model; a, c, cultured with unconditioned fresh medium; b, d, cultured with ECCM

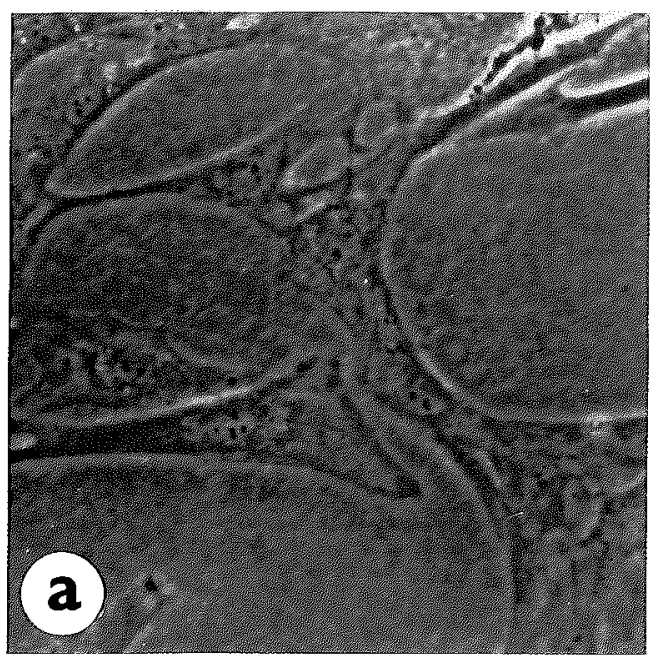

equivalents. The present study was performed to know the reason for this high activity of collagenase production.

In this paper, we clearly demonstrate the presence of a stimulator for the synthesis of collagenase in fibroblasts. Up to now several factors have been reported which activate the collagenase production in fibroblasts, and are collectively called cytokines (46). Interleukin $1(10,36,37,43,54)$, tumor necrosis factor (TNF) (12) and platelet-derived growth factor (2) increase collagenase production, whose molecular weights are $12 \mathrm{~K}-18 \mathrm{~K}(2,41), 45 \mathrm{~K}$ (42) and $28 \mathrm{~K}-31 \mathrm{~K}(45)$, respectively. The molecular weight of the factor we found is $48 \mathrm{~K}$. Interleukin $\mathrm{I}$ is produced mainly by monocytes and macrophages and also by other cells including keratinocytes (40). TNF are produced mainly by macrophages (7). These cytokines are effective on fibroblasts cultured on the plastic as a monolayer, whereas the factor reported in the present paper does not exert any stimulating action on the monolayered cells. It thus appears that the factor reported in the present study is different in its nature from these cytokines.

Corneal epithelial cells have been reported to produce cytokines with molecular weights of $20 \mathrm{~K}, 54 \mathrm{~K}$ and $\geqq 90 \mathrm{~K}$ which stimulate collagenase production in stromal cells (29-31). The similar cytokines were found also in adult

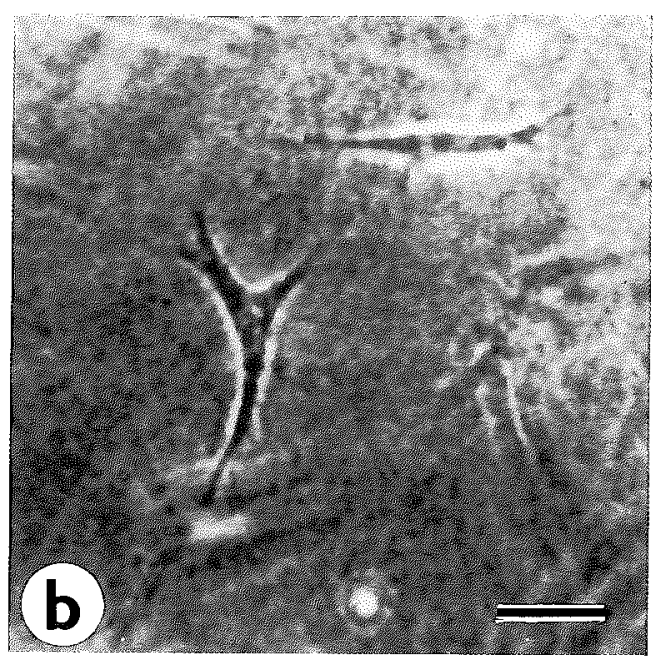

Fig. 11 Shape of fibroblasts cultured for 4 days on the plastic (a) or in lattices of hydrated collagen fibrils (b). Bar, $50 \mu \mathrm{m}$ 
and fetal epidermal cells of rabbit skin, whose apparent molecular weights were $20.5 \mathrm{~K}$ and $55 \mathrm{~K}$ (32). These are potent stimulators for collagenase production in dermal cells cultured on the plastic, suggesting that these cytokines are different in their nature from the stimulator found in the present study. Johnson-Wint (30) noticed that cytochalasin B significantly potentiates the enzyme production in connective tissue cells in response to epidermal cytokines. This indicates the importance of cell shape for the cytokines in cell interactions, which is also demonstrated in the present study.

The epidermal cell-derived factor is active on fibroblasts populated in three-dimensional lattices of collagen fibrils, where the cells differ in their shape from those cultured on the plastic. Cells in the lattice are slim and spindle-shaped, with prominent cytoplasmic protrusions. The shape of cells is closely associated with the arrangement of cytoskeletons. It is thus relevant to point out that drugs such as cytochalasin B, colchicine, and phorborester, which interfere with cytoskeletons, are known to induce collagenase in fibroblasts $(8,14,25$, 26). It appears that some specific arrangement of cytoskeletons is essential for cells to respond to the stimulator of collagenase production (9). Aggeler et al. (1) studied collagenase synthesis in rabbit synovial fibroblasts which had been treated with a variety of agents affecting cell morphology (12-o-tetradecanoylphorbol-13-acetate, cytochalasins B and $\mathrm{D}$, trypsin, chymotrypsin, and trifluoperazine), and found a good correlation between the extent of cell-shape change and the extent of collagenase gene expression.

Unemori and Werb (52) investigated the collagenase production in rabbit synovial fibroblasts cultured on and in hydrated collagen gels and pointed out the importance of reorganization of polymerized actin for triggering the induction of procollagenase. It is possible that collagen fibrils induce some specific cell shape by interacting microfilaments via the cell membrane, and this particular cell shape allows the cell to respond to the factor and express collagenase genes. This postulation is further supported by the observation that collagen modulates cell shape and cytoskeletons of fibroblasts $(51,59)$.

Epidermal cells, which are cultured less than 5 days and show normal appearance, do not produce the stimulator. The cells older than 7 days appear to be deteriorated and start to release the factor. It thus seems that the stimulator we found may be expressed in abnormal epidermal cells as a sort of emergency signal, but not expressed in intact epidermal cells. Though biochemical characterization of this stimulator is still under investigation, all available data indicate that the stimulator is a unique and new factor which belongs to cytokines.

Received for publication 14 March 1990; and in revised form 25 April 1990

\section{REFERENCES}

1. Aggeler J., Frisch S. M. and Werb Z. (1984) Changes in cell shape correlate with collagenase gene expression in rabbit synovial fibroblasts. J. Cell Biol. 98, 1662-1671

2. Bauer E. A., Cooper T. W., Huang J. S., Altman J, and Deuel T. F. (1985) Stimulation of in vitro human skin collagenase expression by platelet-derived growth factor. Proc. Natl. Acad. Sci. USA 82, 4132-4136

3. Bauer E. A., Kronberger A., Valle K.-J., JEFFREY J. J. and EISEN A. Z. (1985) Glucocorticoid modulation of collagenase expression in human skin fibroblast cultures. Evidence for pre-translational inhibition. Biochim. Biophys. Acta 825, 227-235

4. Bell E., Ehrlich H. P., Buttle D. J. and NAKATSUJI T. (1981) Living tissue formed in vitro and accepted as skin-equivalent tissue of full thickness. Science 211, 1052-1054

5. Bell E., Sher S., Hull B., Merrill C., Rosen S., Chamson A., Asselineau D., Dubertret L., Coulomb B., Lapiere C., Nusgens B. and Neveux Y. (1983) The reconstitution of living skin. J. Invest. Dermatol. 81, 2s-10s

6. Bergman I. and Loxley R. (1963) Two improved and simplified methods for the spectrophotometric determination of hydroxyproline. Anal. Chem. 35, 1961-1965

7. Beutler B. and Cerami A. (1987) Cachectin: More than a tumor necrosis factor. New Engl. J. Med. 316, 379-385

8. BRINCKeRHOFF C. E. and HaRRIS E. D. (1981) Modulation by retinoic acid and corticosteroids of collagenase production by rabbit synovial fibroblasts treated with phorbol myristate acetate or poly(ethylene glycol), Biochim. Biophys. Acta 677, 424-432

9. Brinckerhoff C. E., McMillan R. M., Fahey J. V. and Harris E. D. (1979) Collagenase pro- 
duction by synovial fibroblasts treated with phorbol myristate acetate. Arthritis Rheum. 22, 1109-1116

10. Chin J., Cameron P. M., Rupp E. and Schmidt J. A. (1987) Identification of a high-affinity receptor for native human interleukin $1 \beta$ and interleukin $1 \alpha$ on normal human lung fibroblasts. J. Exp. Med. 165, 70-86

11. Cutroneo K. R., Sterling K. M. and Shull S. (1986) Steroid hormone regulation of extracellular matrix proteins. In Regulation of Matrix Accumulation (ed. Меснам R. P.) Academic Press, New York, pp. 119-176

12. Dayer J.-M., Beutler B. and Cerami A. (1985) Cachectin/tumor necrosis factor stimulates collagenase and prostaglandin $\mathrm{E}_{2}$ production by human synovial cells and dermal fibroblasts. $J$. Exp. Med. 162, 2163-2168

13. Dayer J.-M., Bréard J., Chess L. and Krane S. M. (1979) Participation of monocyte-macrophages and lymphocytes in the production of a factor that stimulates collagenase and prostaglandin release by rheumatoid synovial cells. $J$. Clin. Invest. 64, 1386-1392

14. Dayer J.-M. and Krane S. M. (1978) PGE modulates collagenase production by cultured adherent rheumatoid synovial cells. Clin. Res. 26, 513A

15. Dayer J.-M., Roelke M. S. and Krane S. M. (1984) Effects of prostaglandin $E_{2}$, indomethacin, trifluoperazine and drugs affecting the cytoskeleton on collagenase production by cultured adherent rheumatoid synovial cells. Biochem. Pharmacol. 33, 2893-2899

16. Dayer J.-M., Russell R. G. G. and Krane S. M. (1977) Collagenase production by rheumatoid synovial cells: Stimulation by a human lymphocyte factor. Science 195, 181-183

17. Elsdale T. and Bard J. (1972) Collagen substrate for studies on cell behavior. J. Cell Biol. 54, 626-637

18. Folkman J, and Haudenschild C. (1980) Angiogenesis in vitro. Nature 288, 551-556

19. Grillo H. C. and Gross J. (1967) Collagenolytic activity during mammalian wound repair. Develop. Biol. 15, 300-317

20. Grinnell F. and Lamke C. R. (1984) Reorganization of hydrated collagen lattices by human skin fibroblasts. J. Cell Sci. 66, 51-63

21. Guidry C. and Grinnell F. (1985) Studies on the mechanism of hydrated collagen gel reorganization by human skin fibroblasts. J. Cell Sci. 79, 67-81

22. Guidry C. and Grinnell F. (1987) Heparin modulates the organization of hydrated collagen gels and inhibits gel contraction by fibroblasts. J. Cell. Biol. 104, 1097-1103

23. HAM R. G. (1981) Survival and growth require- ments of nontransformed cells. In Tissue Growth Factors (ed. BASERGA R.) Springer-Verlag, Berlin, pp. 13-88

24. HaRris A. K., Stopak D. and Wild P. (1981) Fibroblast traction as a mechanism for collagen morphogenesis. Nature 290, 249-251

25. Harris E. D., ReYnolds J. J. and Werb Z. (1975) Cytochalasin B increases collagenase production by cells in vitro. Nature 257, 243-244

26. Harris E. D., Welgus H. G. and Krane S. M. (1984) Regulation of the mammalian collagenases. Collagen Rel. Res. 4, 493-512

27. Hauser C., Saurat J.-H., Jaunin F., Sizonenko S. and DAYER J. M. (1985) Cultured human epidermis cells produce cell-associated interleukin 1-like prostaglandin $\mathrm{E}_{2}$ - and collagenasestimulating factors. Biochim. Biophys. Acta 840 $350-355$

28. JEFFREY J. J. (1986) The biological regulation of collagenase activity. In Regulation of Matrix Accumulation (ed. Меснам R. P.) Academic Press, New York, pp. 53-98

29. JohNSON-Muller B. and Gross J. (1978) Regulation of corneal collagenase production: Epithelial-stromal cell interactions. Proc. Natl. Acad. Sci. USA 75, 4417-4421

30. Johnson-Wint B. (1980) Regulation of stromal cell collagenase production in adult rabbit cornea: In vitro stimulation and inhibition by epithelial cell products. Proc. Natl. Acad. Sci. USA 77, 5331-5335

31. JohNSON-Wint B. and Bauer E. A. (1985) Stimulation of collagenase synthesis by a 20,000-dalton epithelial cytokine. J. Biol. Chem. 260, 2080-2085

32. Johnson-Wint B. and Gross J. (1984) Regulation of connective tissue collagenase production: Stimulators from adult and fetal epidermal cells. J. Cell Biol. 98, 90-96

33. Kishi J. and Hayakawa T. (1984) Purification and characterization of bovine dental pulp collagenase inhibitor. J. Biochem. 96, 395-404

34. Kitano Y. and Okada N. (1983) Separation of the epidermal sheet by dispase. Brit. J. Dermatol. 108, 555-560

35. Mauch C., Hatamochi A., Scharffetter K. and KRIEG T. (1988) Regulation of collagen synthesis in fibroblasts within a three-dimensional collagen gel. Exp. Cell Res. 178, 493-503

36. McCroskery P. A., Arai S., Amento E. P. and Krane S. M. (1985) Stimulation of procollagenase synthesis in human rheumatoid synovial fibroblasts by mononuclear cell factor/interleukin 1. FEBS Lett. 191, 7-12

37. Mizel S. B., Dayer J.-M., Krane S. M. and Mergenhagen S. E. (1981) Stimulation of rheumatoid synovial cell collagenase and prostaglandin production by partially purified lym- 
phocyte-activating factor (interleukin 1). Proc. Natl. Acad. Sci. USA 78, 2474-2477

38. Murphy G. and Docherty A. J. P. (1988) Molecular studies on the connective tissue metalloproteinases and their inhibitor TIMP. In The Control of Tissue Damage (ed. GLAUERT A. M.) Elsevier, Amsterdam, pp. 223-241

39. Nishikawa A and Yoshizato K. (1985) Epidermal cells of the anuran tadpole tail: Its isolation and characterization in vitro. Zool. Sci. 2, 201211

40. Oppenheim J. J., Kovacs E. J., Matsushima K. and Durum S. K. (1986) There is more than one interleukin 1. Immunol. Today 7, 45-56

41. Oppenheim J. J., Stadler B. M., Siraganian R. P., Mage M. and Mathieson B. (1982) Lymphokines: their role in lymphocyte responses. Properties of interleukin 1. Fed. Proc. Fed. Amer. Soc. Exp. Biol. 41, 257-262

42. Pennica D., Nedwin G. E., Hayflick J. S., Seeburg P. H., Derynck R., Palladino M. A., Kohr W. J., Aggarwal B. B. and Goeddel D. V. (1984) Human tumour necrosis factor: precursor structure, expression and homology to lymphotoxin. Nature 312, 724-729

43. Postlethwate A. E., Lachman L. B., MaInaRdi C. L. and Kang A. H. (1983) Interleukin 1 stimulation of collagenase production by cultured fibroblasts. J. Exp. Med. 157, 801806

44. Rojkind M., Gatmaitan Z., Mackensen S., Giambrone M.-A., Ponce P. and Reid L. M. (1980) Connective tissue biomatrix: its isolation and utilization for long-term cultures of normal rat hepatocytes. J. Cell Biol. 87, 255-263

45. Ross R. (1981) The platelet-derived growth factor. In Tissue Growth Factors (ed. BASERGA R.) Springer-Verlag, Berlin, pp. 133-159

46. Saklatvala J. and Sarsfield S. J. (1988) How do interleukin 1 and tumor necrosis factor induce degradation of proteoglycan in cartilage? In The Control of Tissue Damage (ed. Glauert A. M.) Elsevier, Amsterdam, pp. 97108

47. Sarber R., Hull B., Merrill C., Soranno T. and BELL E. (1981) Regulation of proliferation of fibroblasts of low and high population doubling levels grown in collagen lattices. Mech. Age. Dev. 17, 107-117

48. StopaK D. and Harris A. K. (1982) Connective tissue morphogenesis by fibroblast traction. I. Tissue culture observations. Develop. Biol. 90, 383-398
49. Strom S. C. and Michalopoulos G. (1982) Collagen as a substrate for cell growth and differentiation. Meth. Enzymol. 82, 544-555

50. Takahashi H., Sano K., Yoshizato K., Shioya N. and SASAKI K. (1985) Comparative studies on methods of isolating rat epidermal cells. Ann. Plast. Surg. 14, 258-266

51. Tomasek J. J., Hay E. D. and Fujiwara K. (1982) Collagen modulates cell shape and cytoskeleton of embryonic corneal and fibroma fibroblasts: Distribution of action, $\alpha$-actinin, and myosin. Develop. Biol. 92, 107-122

52. UNEMORI E. N. and WerB Z. (1986) Reorganization of polymerized actin: A possible trigger for induction of procollagenase in fibroblasts cultured in and on collagen gels. J. Cell Biol. 103, 1021-1031

53. van Buul-Wortelboer M. F., Brinkman H. J. M., Dingemans K. P., de Groot Ph. G., van AKEN W. G. and vaN Mourik J. A. (1986) Reconstitution of the vascular wall in vitro. A novel model to study interactions between endothelial and smooth muscle cells. Exp. Cell Res. 162, 151-158

54. Wahl L. M., Wahl S. M., Mergenhagen S. E. and Martin G. R. (1975) Collagenase production by lymphokine-activated macrophages. Science 187, 261-263

55. Welgus H. G. and Stricklin G. P. (1983) Human skin fibroblast collagenase inhibitor. $J$. Biol. Chem. 258, 12259-12264

56. Wooley D. E. (1984) Mammalian collagenases. In Extracellular Matrix Biochemistry (ed. PIEz K. A. and Reddi, A. H.) Elsevier, New York, pp. 119-157

57. Yoshizato K., Kikuyama S. and Shioya N. (1980) Stimulation of glucose utilization and lactate production in cultured human fibroblasts by thyroid hormone. Biochim. Biophys. Acta 627, 23-29

58. Yoshizato K., Nishikawa A., Taira T, Koganel Y., Yamamoto N., Kishi J, and HayaKAWA T. (1986) A reconstituted skin: Dermalepidermal interactions in collagenolysis and cell morphology. Biomedical Res. 7, 219-231

59. Yoshizato K., Taira T. and Yamamoto N. (1985) Growth inhibition of human fibroblasts by reconstituted collagen fibrils. Biomedical Res. 6, 61-71

60. Yoshizato K., Taira T., Yamamoto N. and SASAKI K. (1985) Remodeling of collagen: An in vitro model of connective tissue. Biomedical Res. 6, 287-296 